\title{
Porphyromonas gingivalis lipopolysaccharide promotes T-hel per17 cell differentiation by upregulating Delta-like ligand 4 expression on CD14 ${ }^{+}$monocytes
}

\author{
Chi Zhang ${ }^{1,2}$, Chenrong $\mathbf{X u}^{3}$, Li Gao ${ }^{1,2}$, Xiting Li ${ }^{1,2}$, Chuanjiang Zhao ${ }^{\text {Corresp. } 1,2}$ \\ 1 Department of Periodontology, Hospital of Stomatology, Sun Yat-sen University, Guangzhou, China \\ 2 Guangdong Provincial Key Laboratory of Stomatology, Guanghua School of Stomatology, Sun Yat-sen University, Guangzhou, China \\ 3 Department of Periodontology, Guangdong Provincial Hospital of Stomatology, Stomatological Hospital of Southern Medical University, Guangzhou, \\ China \\ Corresponding Author: Chuanjiang Zhao \\ Email address: zhaochj@mail.sysu.edu.cn
}

Backgroud : To investigate the effect and mechanism of Porphyromonas gingivalis ( $P$. gingivalis ) lipopolysaccharide (LPS) on Th17 cell differentiation mediated by CD14 ${ }^{+}$monocytes.

Methods : $P$. gingivalis LPS-activated $\mathrm{CD} 14^{+}$monocytes were co-cultured with $\mathrm{CD} 4{ }^{+} \mathrm{T}$ cells in different cell ratios. An indirect co-culture system was also established using transwell chambers. Furthermore, anti- Delta-like ligand 4 (DII-4) antibody was used to investigate the role of DIl-4 in Th17 cell response.The mRNA expression was analyzed using quantitative reverse transcription-polymerase chain reaction, and secreted cytokines in culture supernatant were detected using enzyme-linked immunosorbent assay. Flow cytometry was used to determine the frequencies of Th17 cells. IL-17 protein expression levels were determined using western blotting assay.

Results : P. gingivalis LPS increased the expressions of interleukin ( IL)-1 $\beta$, IL-6, IL-23 and transforming growth factor (TGF)- $\beta$ in CD14 ${ }^{+}$monocytes. Th17 cell frequency upregulated, which is not solely cytokine-dependent but rather requires cell-cell contact with activated monocytes, particularly in the 1:10 cell ratio. Furthermore, $P$. gingivalis LPS increased t he expression of DIl-4 on CD14 ${ }^{+}$monocytes, whereas the anti- Dll-4 a ntibody decreased the response of Th17 cells. The results suggest that $P$. gingivalis LPS enhances Th17 cell response via Dll-4 upregulation on CD14 ${ }^{+}$monocytes. 
1 Porphyromonas gingivalis lipopolysaccharide promotes $\mathrm{T}$-helper17 cell differentiation by

2 upregulating Delta-like ligand 4 expression on $\mathrm{CD}^{+} 4^{+}$monocytes

3 Chi Zhang ${ }^{1,2}$, Chenrong $\mathrm{Xu}^{3}$, $\mathrm{Li} \mathrm{Gao}^{1,2}$, Xiting $\mathrm{Li}^{1,2}$, Chuanjiang Zhao ${ }^{1,2}$

$4{ }^{1}$ Department of Periodontology, Hospital of Stomatology, Sun Yat-sen University, Guangzhou, 5 China.

$6{ }^{2}$ Guangdong Provincial Key Laboratory of Stomatology, Guanghua School of Stomatology, Sun 7 Yat-sen University, Guangzhou, China.

$8{ }^{3}$ Department of Periodontology, Guangdong Provincial Hospital of Stomatology, Stomatological

9 Hospital of Southern Medical University, Guangzhou, China.

10 Corresponding author:

11 Chuanjiang Zhao Road, Guangzhou, 510055, China. 
31

32

33

34

35

36

37

38

39

40

41

42

43

44

45

46

47

48

50

51

52

53

54

55

56

57

ABSTRACT

Backgroud: To investigate the effect and mechanism of Porphyromonas gingivalis

(P. gingivalis ) lipopolysaccharide (LPS) on Th17 cell differentiation mediated by CD14 monocytes.

Methods: $P$. gingivalis LPS-activated $\mathrm{CD} 14^{+}$monocytes were co-cultured with $\mathrm{CD}^{+} \mathrm{T}$ cells in different cell ratios. An indirect co-culture system was also established using transwell chambers. Furthermore, anti-Delta-like ligand 4 (D11-4) antibody was used to investigate the role of D1l-4 in Th17 cell response. The mRNA expression was analyzed using quantitative reverse transcriptionpolymerase chain reaction, and secreted cytokines in culture supernatant were detected using enzyme-linked immunosorbent assay. Flow cytometry was used to determine the frequencies of Th17 cells. IL-17 protein expression levels were determined using western blotting assay.

Results: $P$. gingivalis LPS increased the expressions of interleukin (IL)-1 $\beta$, IL-6, IL-23 and transforming growth factor (TGF)- $\beta$ in $\mathrm{CD} 14^{+}$monocytes. Th17 cell frequency upregulated, which is not solely cytokine-dependent but rather requires cell-cell contact with activated monocytes, particularly in the 1:10 cell ratio. Furthermore, $P$. gingivalis LPS increased the expression of Dll4 on $\mathrm{CD}_{14}{ }^{+}$monocytes, whereas the anti-Dll-4 antibody decreased the response of Th17 cells. The results suggest that $P$. gingivalis LPS enhances Th17 cell response via Dll-4 upregulation on $5 \mathrm{CD} 14^{+}$monocytes. 


\section{INTRODUCTION}

63

Periodontitis is a chronic inflammatory disease, characterized by attachment loss and alveolar bone resorption ( $\mathrm{Di}$ Benedetto et al., 2013). It is caused by the accumulation of pathogenic microorganisms on the teeth, which stimulate local inflammatory and immune reactions. Although periodontitis is caused by pathogenic bacteria, its progression and prognosis are highly influenced by $\mathrm{CD}^{+} \mathrm{T}$ cell-mediated host immune response (Baker et al., 2001; Campbell et al., 2016). Increasing evidence has shown that T-helper 17 (Th17) cells that produce interleukin (IL)-17 (also known as IL-17A) (Park et al., 2005; Harrington et al., 2005) are involved in the pathogenesis of periodontitis and alveolar bone destruction (Adibrad et al., 2012; Cardoso et al., 2009). It has been reported that the percentage of IL-17 producing CD4 ${ }^{+} \mathrm{T}$ cells was higher in periodontitis lesions than in healthy tissues and gingivitis lesions (Dutzan et al., 2016; Okui et al., 2012). By using biopsies from periodontitis patients, Allam et al. (2011) reported that the number of IL-17 positive

4 T cells was related to the severity of periodontal inflammation. Therefore, study on the mechanism of Th17 cell differentiation in the periodontal inflammatory context is important for understanding the immunopathology of periodontitis.

7 In the periodontal inflammatory environment, antigen-presenting cells (APCs), such as monocytes, dendritic cells (DCs), and other lymphocytes are rapidly recruited to inflammatory infection sites to participate in immune regulation. It is well known that the adaptive immune response mediated by microorganism-activated APCs is responsible for the progression and 
81 prognosis of periodontitis (Cheng et al., 2016). APCs provide activated signal molecules and a

82 series of specific cytokines that promote Th17 cell differentiation (Novak et al., 2010; Gutcher\&

83 Becher, 2007). Monocytes are often considered as DCs precursors of DCs, and exert a distinct role

84 in the shaping of immune response (Geissmann et al., 2008). Several studies have confirmed that

85 monocytes, one of the APCs, secrete IL-23, IL-6, and IL-1 $\beta$, and contribute to Th17 cell

86 differentiation (Segura et al., 2013; Evans et al., 2009).

87 Cell contact between monocytes and $\mathrm{T}$ cells plays an important role in inducing $\mathrm{CD}^{+} \mathrm{T}$ cell 88 differentiation (Wittmann, Alter \& Stünkel, 2004; Roberts, Dickinson \& Taams, 2015). A recent 89 study has shown that activated $\mathrm{CD} 14^{+}$monocytes effectively induced Th17 cell differentiation 90 only after directly contacted with $\mathrm{CD}^{+} \mathrm{T}$ cells in vitro (Yang et al., 2017). Another study reported 91 that the proportion of Th17 cells in the monocytes and $\mathrm{CD}^{+} \mathrm{T}$ cell co-culture systems decreased 92 after blocking the TNF- $\alpha$ expressed on the surface of monocytes (Rossol, Meusch \& Pierer, 2007).

93 Thus, the expression of intercellular adhesion molecules and co-stimulation molecules on 94 monocytes is important in regulating the Th17 pathway.

95 Notch ligands and receptors expressed on $\mathrm{CD}^{+} \mathrm{T}$ cells and APCs have been found to be 96 involved in Th17 cell differentiation (Ito et al., 2012; Keerthivasan et al., 2011). Mammals carry 97 four Notch receptors (i.e., Notch-1, 2, 3, and 4), and five Notch ligands (i.e., Jagged-1, Jagged-2, 98 and Delta-like 1, 3, and 4 (D1l-1, 3, 4)) (Bray, 2006). It has been demonstrated that Dll-4 activation 99 of Notch may represent an important signal that instructs the development of effector T cells (Meng 100 et al.,2016). Dll-4 drives Th17 cell differentiation by upregulating the transcription factor retinoid101 related orphan receptor $\gamma \mathrm{t}(\mathrm{ROR} \gamma \mathrm{t})$ in vitro (Mukherjee et al., 2009). In addition, DCs activation 102 by Escherichia coli LPS could induce Th17 cell differentiation through upregulating the 
103 expression of Dll-4 (Jiang et al., 2015), suggesting a possible role of Dll-4 in modulating Th17

104 response elicited by periodontal pathogens.

105 Porphyromonas gingivalis is an important periodontopathic bacterium, responsible for bone 106 resorption in periodontitis (Hajishengallis, 2009). P. gingivalis-derived lipopolysaccharide (LPS)

107 is one of the main pathogenic factors in periodontitis and contributes significantly to the overall 108 immune response against bacterial infection (Jain \& Darveau, 2010; Seo et al., 2012; Su et al.,

109 2015). Our previous study showed that LPS from P. gingivalis directly promotes Th17 cell 110 differentiation via toll-like receptor-2 in vitro (Zhang et al., 2019). In addition to the direct effect 111 of periodontal pathogens and related virulence factors, immune cells present in the periodontal 112 inflammatory microenvironment have also been shown to play an important role in regulating 113 Th17 cell differentiation (Moutsopoulos et al., 2012). Moreover, it has been demonstrated that $P$. 114 gingivalis activated $\mathrm{CD} 14^{+}$monocytes increased IL-17 production by human $\mathrm{CD} 4^{+} \mathrm{T}$ cells in vitro 115 (Cheng et al., 2016). However, the possible mechanism underlying the regulation of Th17 cell 116 differentiation induced by $P$. gingivalis activated $\mathrm{CD}^{+} 4^{+}$monocytes is still undetermined.

117 Therefore, in order to gain a more comprehensive understanding of Th17 cell immunity in 118 periodontal pathogenesis, we established cell co-culture systems of $\mathrm{CD} 4^{+} \mathrm{T}$ cells and $P$. gingivalis 119 LPS-activated $\mathrm{CD} 14^{+}$monocytes in vitro, to detect the Th17 cell differentiation, and further 120 analyze the function of Dll-4 in the process.

\section{MATERIALS AND METHODS}

\section{$123 \mathbf{C D 1 4}^{+}$monocytes and $\mathrm{CD}^{+} \mathrm{T}$ cell sorting}

124 Human blood samples were obtained from six healthy donors aged 18 to 23 years. The donors 125 were recruited from the North Campus of Sun Yat-Sen University. All subjects enrolled in this 
126 study gave their informed consent before participating. This study was approved by the Ethics

127 Committee of the Hospital of Stomatology of Sun Yat-Sen University, China (ERC-2014-08) and

128 was conducted in accordance with the Helsiniki Declaration of 1975. Peripheral blood

129 mononuclear cells (PBMCs) were isolated by density gradient centrifugation using Ficoll-

130 Hypaque solution (STEMCELL, Vancouver, BC, CA) from fresh peripheral blood. CD14 ${ }^{+}$

131 monocytes ( $>94 \%$ purity as confirmed by flow cytometry) and CD $4^{+} \mathrm{T}$ cells ( $>96 \%$ purity) were

132 sorted using Anti-Human CD14 Magnetic Particles-DM (BD Biosciences, San Jose, CA, USA)

133 and a negative immunomagnetic selection for human $\mathrm{CD}^{+} \mathrm{T}$ Cell Enrichment Set-DM (BD

134 Biosciences).

135

\section{Cell culture and stimuli}

137 Purified $\mathrm{CD}^{+} 4^{+}$monocytes and $\mathrm{CD}^{+} \mathrm{T}$ cells were cultured in RPMI 1640 medium (Life

138 Technologies, Grand Island, NY, USA) supplemented with 10\% fetal bovine serum (FBS) and 1\%

139 penicillin/streptomycin (Sigma-Aldrich, St. Louis, MO, USA), in a humidified atmosphere of 5\%

$140 \mathrm{CO}_{2}$ at $37^{\circ} \mathrm{C} . \mathrm{CD} 14^{+}$monocytes $\left(1 \times 10^{6} / \mathrm{mL}\right)$ were either treated for $24 \mathrm{~h}$ with $1 \mu \mathrm{g} / \mathrm{mL}$ of LPS-

141 PG Ultrapure (InvivoGen, San Diego, CA, USA) or left untreated as controls. CD4 ${ }^{+}$T cells were

142 stimulated for $24 \mathrm{~h}$ with plate-bound $2 \mu \mathrm{g} / \mathrm{mL}$ of anti-CD3 $\mathrm{mAb}$ and $1 \mu \mathrm{g} / \mathrm{mL}$ of anti-CD28 mAb

143 (BD Biosciences).

144

\section{Co-culture and transwell assays}

146 Activated $\mathrm{CD}^{+} \mathrm{T}$ cells $\left(1 \times 10^{6} / \mathrm{mL}\right)$ were cultured in 24 -well plates. The $\mathrm{CD} 14^{+}$monocytes

147 treated with $P$. gingivalis LPS, or the untreated $\mathrm{CD} 14^{+}$monocytes were co-cultured with the 148 activated $\mathrm{CD}^{+} \mathrm{T}$ cells in 1:1, 1:5, or 1:10 cell ratios and were incubated for 5 days in a humidified 
149 atmosphere of $5 \% \mathrm{CO}_{2}$ at $37^{\circ} \mathrm{C}$. The $\mathrm{CD}^{+} 4^{+}$monocytes activated by $P$. gingivalis LPS were

150 washed 3 times with PBS to remove excess $P$. gingivalis LPS before co-cultured with CD4 ${ }^{+} \mathrm{T}$

151 cells.

152

153 Transwell assay

154 For transwell assays, activated $\mathrm{CD} 4^{+} \mathrm{T}$ cells and $\mathrm{CD} 14^{+}$monocytes were separated by an insert 155 containing a $0.4-\mu \mathrm{m}$ semi-permeable membrane. $\mathrm{CD} 14^{+}$monocytes $\left(1 \times 10^{6} / \mathrm{mL}\right)$ were inoculated 156 into the upper chamber, and activated $\mathrm{CD}^{+} \mathrm{T}$ cells in a 1:10 cell ratio were inoculated into the 157 lower chamber. The cells were cultured for 5 days in a humidified atmosphere of $5 \% \mathrm{CO}_{2}$ at $37^{\circ} \mathrm{C}$. 158

159 Dll-4 blocking assay

$160 \mathrm{CD} 4^{+}$monocytes were pretreated with 5 or $10 \mu \mathrm{g} / \mathrm{mL}$ anti-Dll-4 antibody (BD Biosciences) for $16190 \mathrm{~min}$ prior to the addition of $P$. gingivalis LPS, and Mouse IgG1, $\kappa$ Isotype Control (BD 162 Biosciences) was used as the isotype control. The cells were then incubated with $1 \mu \mathrm{g} / \mathrm{mL}$ of $P$. 163 gingivalis LPS for $24 \mathrm{~h}$ and were co-cultured with activated CD4 ${ }^{+} \mathrm{T}$ cells in a 1:10 ratio for 5 days 164 in a humidified atmosphere of $5 \% \mathrm{CO}_{2}$ at $37^{\circ} \mathrm{C}$. Unblocked groups were used as controls.

166 RNA isolation and quantitative reverse-transcription real-time polymerase chain (qRT167 PCR) reaction

168 RNA was extracted using TRIzol reagent (Invitrogen, Carlsbad, CA, USA), and the RNA 169 concentration was determined using a Nanodrop 2000 spectrophotometer (Thermo Fisher 170 Scientific, Waltham, MA, USA). Reverse transcription was performed using PrimeScript RT 171 Master Mix (TaKaRa Biotech, Tokyo, Japan) to provide a cDNA template, and the SYBR Green 
172 I Master Kit was used to perform PCR in a Light Cycler $^{\circledR} 480$ (Roche, Indianapolis, IN, USA).

173 Table 1 lists all the primer sequences used for the target gene. $\beta$-actin was used as a loading control.

174 The relative gene expression level was calculated using the $2^{-\Delta \Delta \mathrm{Ct}}$ method.

175

176 Enzyme-linked immunosorbent assay (ELISA) analysis

177 Secreted cytokines in culture supernatant were detected using ELISA. The concentrations of IL$1781 \beta$, IL-6, IL-23 and TGF- $\beta$ in the cell culture of $P$. gingivalis LPS-treated CD14 ${ }^{+}$monocytes were 179 measured using the Quantikine Human IL-1 $\beta$, IL-6, IL-23 and TGF- $\beta$ ELISA Kit (R\&D system, 180 Minneapolis, MN, USA) according to the manufacturer's instructions. The concentration of IL181 17A in the co-culture of $\mathrm{CD}^{+} \mathrm{T}$ cells and $\mathrm{CD}^{+} 4^{+}$monocytes was measured using the Quantikine 182 Human IL-17A ELISA Kit (R\&D system).

183

\section{Flow cytometry}

185 For surface staining of the stimulated cells, anti-CD4-APC (BD Biosciences), anti-CD3-PERCP, 186 anti-CD8-FITC, anti-CD14-FITC (eBioscience, San Diego, CA, USA) were used. Fc receptor

187 binding inhibitor antibody(eBioscience) was used to inhibit the non-specific Fc-gamma receptor 188 (FcgammaR)-mediated binding of mouse monoclonal antibodies. Fix Viability Dye (eBioscience) 189 was used to stain and exclude dead cells from the analyses. For intracellular staining, cells were 190 restimulated on $50 \mathrm{ng} / \mathrm{mL}$ phorbol 12-myristate 13-acetate (Sigma-Aldrich) and $250 \mathrm{ng} / \mathrm{mL}$ 191 ionomycin (Sigma-Aldrich) in the presence of $10 \mu \mathrm{g} / \mathrm{mL}$ of brefeldin A (Sigma-Aldrich) for the 192 last $5 \mathrm{~h}$ of culture. Cells were fixed and permeabilized using the Cytofix/Cytoperm Fixation and 193 Permeabilization Kit (BD Biosciences), labeled with anti-IL-17-PE (eBiosciences), and analyzed 194 on the Gallios system using the Kaluza software (Beckman Coulter, CA, USA). 


\section{Western blot analysis}

197 Cells were collected and lysed in radioimmunoprecipitation assay (RIPA) buffer containing 1\% 198 phenylmethylsulfonyl fluoride for $30 \mathrm{~min}$. The BCA protein assay kit (Beyotime, Hangzhou, 199 China) was used for total protein quantification. A total of $50 \mu \mathrm{g}$ of protein was loaded per lane, 200 separated by sodium dodecyl sulfate polyacrylamide gel electrophoresis (SDS-PAGE), and 201 electrophoretically transferred onto polyacrylamide difluoride (PVDF) membranes (Merck 202 Millipore, Bedford, MA, USA). The PVDF membrane was blocked for $1 \mathrm{~h}$ with 5\% fat-free dry 203 milk in tris-buffered saline with Tween (TBST) and incubated overnight with 1:500 dilution of IL204 17A primary antibody (Santa Cruz Biotechnology, CA, USA) and 1:1,000 dilution of 205 glyceraldehyde 3-phosphate dehydrogenase (GAPDH) (Cell Signaling Technology, Danvers, MA, 206 USA). The membrane was then washed 3 times with TBST and incubated for $1 \mathrm{~h}$ with a 1:5,000 207 dilution of the secondary antibody (Beyotime). Finally, immunoreactive proteins were visualized 208 using the ECL reagent (Merck Millipore), and the signals were detected using the ImageQuant Las 2094000 mini system (General Electric, Fairfield, CT, USA). The densities of western blotting bands 210 were measured using ImageJ software (National Institutes of Health, Bethesda, MD, USA).

\section{Statistical analysis}

213 SPSS 21.0 statistical software (IBM, Chicago, IL, USA) and Graphpad prism 6.0 (GraphPad 214 Software, San Diego, CA, USA) were used for statistical analysis. Data are presented as mean \pm 215 standard deviation (SD) based on triplicate assays for six independent experiments $(n=6)$. The 216 student's t-test was used for comparion between the two groups. Differences between multiple 
217 groups were assessed using one-way analysis of variance (ANOVA) method with Tukey's post

218 hoc test. A value of $P<0.05$ was considered as significant.

219

\section{RESULTS}

P. gingivalis LPS-treated CD14 ${ }^{+}$monocytes promote Th17 cell differentiation

222 To explore the function of $\mathrm{CD} 14^{+}$monocytes on Th17 cell response, $\mathrm{CD} 14^{+}$monocytes treated 223 with $1 \mu \mathrm{g} / \mathrm{mL}$ of $P$. gingivalis LPS were co-cultured with $\mathrm{CD}^{+} \mathrm{T}$ cells in the ratios of $1: 1,1: 5$, and 224 1:10. The result showed that there was no difference in the mRNA expression of IL-17 and 225 retinoid-related orphan receptor C (RORC) between the $P$. gingivalis LPS-stimulated group and 226 the untreated group in a 1:1 co-culture ratio (Fig. $1 \mathrm{~A}$ and D). However, CD14 ${ }^{+}$monocytes 227 activated by $P$. gingivalis LPS upregulated the mRNA expression of IL-17 and RORC (Fig. 1B, $228 \mathrm{C}, \mathrm{E}$ and F), with the most evident upregulation occurring when cells were cultured in a 1:10 co229 culture ratio (Fig. 1C and F). Moreover, the frequency of Th17 cells increased in all 1:1, 1:5, and $2301: 10$ cell ratios, especially in the 1:10 (Fig. 1G-1J). Thus, the 1:10 co-culture ratio was used for 231 further analyses to explore the mechanism of in vitro Th17 cell differentiation.

232

233

\section{$P$. gingivalis LPS-stimulated CD14 ${ }^{+}$monocytes secrete IL-1 $\beta$, IL-6, IL-23 and TGF- $\beta$}

234 To assess the effect of $P$. gingivalis LPS on monocytes, we used $1 \mu \mathrm{g} / \mathrm{mL}$ of $P$. gingivalis LPS to 235 stimulate $\mathrm{CD} 14^{+}$monocytes. There was an upregulation in the mRNA expression of IL-1 $\beta$, IL-6, 236 TGF- $\beta$, and IL-23 (Fig. 2A-2D), and a similar upregulation of the released protein in the 237 supernatants of stimulated $\mathrm{CD} 14^{+}$monocytes was observed relatively to an unstimulated control 238 in the absence of $P$. gingivalis LPS (Fig. 2E-2H). 
240 Enhancement of Th17 cell differentiation in $\mathrm{CD4}^{+} \mathbf{T}$ cells by $P$. gingivalis LPS-activated

$241 \mathrm{CD}^{+}{ }^{+}$monocytes requires cell-cell contact

242 To confirm the role of soluble cytokines and cell-cell contact in the augmentation of Th17 cell

243 induction by $P$. gingivalis LPS-activated CD14 ${ }^{+}$monocytes, a transwell assay was used, in which

$244 \mathrm{CD} 4^{+}$monocytes and $\mathrm{CD}^{+} \mathrm{T}$ cells were separated by a membrane. The results showed that $P$.

245 gingivalis LPS did not alter the mRNA expression of RORC and IL-17 (Fig. 3A and B).

246 Furthermore, there was no difference in the frequency of Th17 cells between the $P$. gingivalis LPS-

247 stimulated group and the untreated group (Fig. 3C and D).

248

249

$P$. gingivalis LPS increases the expression of Dll-4 mRNA in CD14 ${ }^{+}$monocytes

250 The expressions of Notch ligand Jagged-1 and Dll-4 on APCs have been reported to be associated 251 with Th17 cell differentiation. In the present study, direct cell-cell contact by P. gingivalis LPS252 activated $\mathrm{CD} 14^{+}$monocytes was required to promote the induction of Th17 cells. Therefore, we 253 explored whether Jagged-1 and D11-4 were involved in this process. The expressions of Jagged-1 254 and Dll-4 mRNA were investigated in $1 \mu \mathrm{g} / \mathrm{mL}$ of $P$. gingivalis LPS CD14 ${ }^{+}$monocytes using $\mathrm{qRT}$ -

255 PCR. The results showed that $1 \mu \mathrm{g} / \mathrm{mL}$ of $P$. gingivalis LPS upregulated the expression of Dll-4 256 mRNA in $\mathrm{CD}_{14}^{+}$monocytes (Fig. 4A). However, no changes were observed for Jagged-1 mRNA 257 (Fig. 4B)

Th17 cell differentiation induced by $P$. gingivalis LPS decreased in the presence of a blocking 260 Dll-4 antibody

261 To confirm whether the upregulation of D11-4 expression on CD14 ${ }^{+}$monocytes was involved in 262 Th17 cell differentiation, the CD14 ${ }^{+}$monocytes were pretreated with 5 and $10 \mu \mathrm{g} / \mathrm{mL}$ anti-D1l-4 
263 antibodies for 90 min prior to stimulation with $P$. gingivalis LPS. Flow cytometry demonstrated 264 that the number of differentiated Th17 cells decreased significantly in the 5 and $10 \mu \mathrm{g} / \mathrm{mL}$ D1l-4

265 blocking groups, compared with the unblocked group (Fig. 5A and B). The level of IL-17 protein 266 was determined using western blot, and it showed a significantly increased level in the $P$. gingivalis 267 LPS-stimulated group (Fig. 5C and D) compared with the $P$. gingivalis LPS-unstimulated group. 268 Furthermore, compared with the unblocked group, the expression of IL-17 was significantly 269 reduced in the Dll-4 blocking groups, and the decrease was more obvious in the $10 \mu \mathrm{g} / \mathrm{mL}$ Dll-4 270 blocking group (Fig. 5C and D). To analyze the role of anti-Dll-4 in IL-17 secretion, the 271 concentration of secreted IL-17 in the supernatant of the co-cultured cells was determined using 272 ELISA. As expected, the concentration of IL-17 in the 5 and $10 \mu \mathrm{g} / \mathrm{mL}$ Dll-4 blocking groups was 273 significantly downregulated compared with the unblocked group (Fig. 5E). However, no 274 significant difference was found between the 5 and $10 \mu \mathrm{g} / \mathrm{mL}$ Dll-4 blocking groups (Fig. 5E).

275

276 DISCUSSION

277 Under an inflammatory microenvironment, monocytes can be quickly recruited to the infection 278 sites to participate in an inflammatory process. It has been reported that activated monocytes from 279 rheumatoid arthritis patients specifically induced Th17 cells (Evans et al., 2009). A further study 280 showed that optimal Th17 cell induction required the presence of TLR-activated monocytes in 281 vitro (Evans et al., 2007). Addition of $P$. gingivalis to monocyte/CD4 ${ }^{+} \mathrm{T}$ cell co-cultures promoted 282 a Th17/IL-17 response in a dose- and time-dependent manner (Cheng et al., 2016). Nevertheless, 283 the latest study demonstrates that $P$. gingivalis LPS can directly induce $\mathrm{CD}^{+} \mathrm{T}$ cell differentiation 284 to Th17 cells in vitro without APCs (Zhang et al., 2019). Therefore, in the present study, to rule 285 out the direct influence of $P$. gingivalis LPS on $\mathrm{CD}^{+} \mathrm{T}$ cells, the CD14 $4^{+}$monocytes activated by 
$286 P$. gingivalis LPS were washed 3 times with PBS to remove excess $P$. gingivalis LPS before co287 cultured with $\mathrm{CD}^{+} \mathrm{T}$ cells. The results confirmed that the augmentation of Th17 cells was induced 288 by $\mathrm{CD}_{14}{ }^{+}$monocytes instead of the residual $P$. gingivalis LPS contamination. In addition, our 289 results showed that the $\mathrm{CD}_{1} 4^{+}$monocytes activated by $P$. gingivalis LPS increased the frequency 290 of Th17 cells in all $1: 1,1: 5$, and $1: 10$ cell ratios, especially in the $1: 10$, which indicates that the $291 \mathrm{CD} 14^{+}$monocytes/CD4 ${ }^{+} \mathrm{T}$ cell ratio also has an impact on the Th17 cell induction. Previous studies 292 have also shown that a monocytes/T cell ratio of 1:1 could effectively induce Th17 cell 293 differentiation (Cheng et al., 2016, Yang et al., 2017). However, it has been suggested that antigen 294 treated DCs can possess either an immunogenic or tolerogenic function depending on the DC/T 295 cell ratio. High DC/T cell ratios resulted in inhibition of T cell proliferation, while low DCs ratios 296 displayed enhanced T cell-stimulatory properties and supported T cell proliferation (HöPken et 297 al., 2005). Therefore, the inhibition of $\mathrm{T}$ cell proliferation and immune tolerance induced by high 298 percentage of $\mathrm{CD}_{14}{ }^{+}$monocytes may be the reason for less frequency of Th17 cells in 1:1 and1:5 299 than 1:10 cell ratios.

300 To date, IL-1 $\beta$ and IL-6 are prominent cytokine candidates for the polarization of naive Th 301 cells into Th17 cells (Acosta-Rodriguez et al., 2012), and TGF- $\beta$ combined with IL-6 induces 302 RORC to promote Th17 cell differentiation (Veldhoen et al., 2006). Although IL-23 is not a 303 necessary factor for Th17 cells, it maintains Th17 cell proliferation (Zhou et al., 2007). Segura et 304 al. (2013) blocked IL-1 $\beta$, IL-6, IL-23, and TGF- $\beta$ and observed a decrease in the differentiation 305 ratio of Th17 cells. Moutsopoulos et al. (2012) reported an upregulation of IL-1 $\beta$ and IL-6 306 associated with $P$. gingivalis stimulated-myeloid APCs. In the present study, $P$. gingivalis LPS307 stimulated CD14 ${ }^{+}$monocytes secreted IL-6, IL-1 $\beta$, TGF- $\beta$, and IL-23 proteins. Moreover, the 308 mRNA expression of these cytokines was obviously upregulated, thus indicating that the CD14 
309 monocytes activated by $P$. gingivalis LPS might be related to Th17 cell response. To explore the

310 function of cytokines induced by the $P$. gingivalis LPS in Th17 cell response, the transwell assay

311 was used. However, no difference was observed in Th17 cell differentiation in the presence or

312 absence of $P$. gingivalis LPS when cells were cultured separately. Moreover, the ratio of Th17

313 cells was significantly lower than in direct co-culture, thus indicating that the CD14 $4^{+}$monocytes

314 activated by $P$. gingivalis LPS failed to induce Th17 cell response in the absence of direct cell-cell

315 contact. It can be concluded that cell-cell contact may play pivotal roles in Th17 cell

316 differentiation. Besides, we also simultaneously observed that the cytokine concentrations

317 stimulated by $1 \mu \mathrm{g} / \mathrm{mL}$ of $P$. gingivalis LPS-activated CD14 ${ }^{+}$monocytes were considerably lower

318 than Th17 skewing conditions in vitro. This might be another reason why $P$. gingivalis LPS could

319 not effectively induce Th17 cell differentiation in the absence of direct cell-cell contact. In

320 summary, these results indicate that the induction of Th17 cell differentiation is not solely

321 cytokine-dependent but rather requires cell-cell contact with $P$. gingivalis LPS activated 322 monocytes.

323 It has been reported that cell-cell contact signal, such as adhesion, co-stimulation factors 324 expressed on $\mathrm{CD}_{14}{ }^{+}$monocytes play essential roles in Th17 cell differentiation (Yang et al., 2017;

325 Roberts, Dickinson, \& Taams, 2015). Recent research has shown that the Notch signaling pathway

326 plays a pivotal role in T cell lineage commitment and is involved in the regulation of Th17 cell

327 response (Amsen et al., 2015; Jiao et al., 2014; Keerthivasan et al., 2011). It is well known that

328 the interaction between the Notch receptors and ligands is the starting point for the Notch signaling

329 cascade. Notch ligands expressed on the surface of APCs are associated with Th17 responses, and

330 Jagged-1 and D11-4 are the most widely studied ligand (Higashi et al., 2010; Weng et al., 2017;

331 Wang et al., 2015). In the present study, CD14+ monocytes were activated by $P$. gingivalis LPS, 
332 and the expressions of Jagged-1 and Dll-4 were determined. The results showed that $1 \mu \mathrm{g} / \mathrm{mL} P$.

333 gingivalis LPS upregulated the expression of D1l-4 mRNA but did not affect Jagged-1 mRNA.

334 Higashi's study showed that curdlan stimulation induces an increased level of Jagged-1 mRNA

335 but not Dll-4 in Mo-DCs (Higashi et al., 2010). Tsao et al. (2011) reported increased Jagged-1 on

336 the surface of the macrophages exposed to LPS. In this study, P. gingivalis LPS increased the

337 expression of D11-4 but not Jagged-1. The discrepancy between different studies may be due to the 338 use of different stimuli and may be due to cell specificity.

339 Dll-4-mediated Notch signaling is thought to play a pivotal role in the regulation of Th17 cell 340 response (Jiang et al., 2015). The present study showed P. gingivalis LPS upregulated Dll-4 341 expression on $\mathrm{CD}_{14}{ }^{+}$monocytes. Moreover, $P$. gingivalis LPS enhanced Th17 cell differentiation

342 by cell-cell contact. On the basis of these results, we speculate that the Dll-4 expressed on CD14 343 monocytes correlates with Th17 cell response in the periodontal inflammatory microenvironment.

344 Thus, the mechanism of Th17 cell differentiation was analyzed using a blocking Dll-4 antibody.

345 The results showed that Dll-4 blockade reduced the frequency of Th17 cells, and the IL-17 protein 346 level in the supernatant. These results are consistent with the findings of Mukherjee, who reported 347 that the TLR-mediated stimulation of IL-17 responses depends on the stimulus and that Dll-4 348 protein enhances T cell skewing toward IL-17 production (Mukherjee et al., 2009). Previous 349 studies have reported that blocking Dll-4-Notch signaling in animal models of experimental 350 autoimmune encephalomyelitis and asthma decreased both Th17 response and clinical symptoms 351 severity (Weng et al., 2017; Bassil et al., 2011). Therefore, Dll-4 may present a promising 352 therapeutic target for immunomodulation in the development of periodontitis and deserves further 353 exploration in vivo.

\section{CONCLUSIONS}


cell response in a way that requires cell-cell contact. This upregulation is partially reversed in the

presence of anti-Dll-4, thus indicating that the Notch ligand Dll-4 expressed on the CD14 ${ }^{+}$ monocytes is involved in Th17 cell response.

\section{REFERENCES}

Abusleme L, Moutsopoulos NM. 2017. IL-17: Overview and role in oral immunity and microbiome. Oral Disease. 23:854-865. DOI: 10.1111/odi.12598.

364

365

366

367

368

369

370

371

372

373

374

375

376

377

378

379

380

381

382

383

Acosta-Rodriguez EV, Napolitani G, Lanzavecchia A, \& Sallusto F. 2007. Interleukins $1 \beta$ and 6 but not transforming growth factor- $\beta$ are essential for the differentiation of interleukin 17producing human T helper cells. Nature Immunology 8(9): 942-949 DOI 10.1038/ni1496.

Adibrad M, Deyhimi P, Ganjalikhani, Hakemi M, Behfarnia P, Shahabuei M, \& Rafiee L. 2012. Signs of the presence of Th17 cells in chronic periodontal disease. Journal of Periodontal Research 47(4): 525-531 DOI 10.1111/j.1600-0765.2011.01464.

Allam J, Duan Y, Heinemann F, Winter J, Götz W, Deschner J, Wenghoefer M, Bieber T, Jepsen S, Novak N. 2011. IL-23-producing CD68 ${ }^{+}$macrophage-like cells predominate within an IL-17-polarized infiltrate in chronic periodontitis lesions. Journal of Clinical Periodontology 38(10):879-886 DOI 10.1111/j.1600-051X.2011.01752.x.

Amsen D, Helbig C, \& Backer R A. 2015. Notch in T Cell Differentiation: All Things Considered. Trends in Immunology 36(12): 802-814 DOI 10.1016/j.it.2015.10.007.

Baker P J, Garneau J, Howe L, \& Roopenian DC. 2001. T-cell contributions to alveolar bone loss in response to oral infection with Porphyromonas gingivalis. Acta Odontologica Scandinavica 59(4): 222-225 DOI 10.1080/00016350152509247.

Bassil R, Zhu B, Lahoud Y, Riella LV, Yagita H, Elyaman W, \& Khoury SJ. 2011. Notch ligand delta-like 4 blockade alleviates experimental autoimmune encephalomyelitis by promoting regulatory T cell development. Journal of Immunology 187(5): 2322-2328 DOI 10.4049/jimmunol.1100725.

Bray SJ. 2006. Notch signalling: a simple pathway becomes complex. Nature Reviews Molecular 
Cell Biology 7(9): 678-689 DOI 10.1038/nm2009.

385

386

387

388

389

390

391

392

393

394

395

396

397

398

399

400

401

402

403

404

405

406

407

408

409

410

411

412

413

414

415

416

Campbell L, Millhouse E, Malcolm J, Culshaw S. 2016. T cells, teeth and tissue destruction what do T cells do in periodontal disease? Molecular Oral Microbiology 31(6): 445-456 DOI 10.1111/omi.12144.

Cardoso CR, Garlet GP, Crippa GE, Rosa AL, Junior WM, Silva JS. 2009. Evidence of the presence of $\mathrm{T}$ helper type 17 cells in chronic lesions of human periodontal disease. Oral Microbiology and Immunology 24(1): 1-6 DOI 10.1111/j.1399-302X.2008.00463.x.

Cheng WC, van Asten SD, Burns LA, Evans HG, Walter GJ, Hashim A, Hughes F J. 2016. Periodontitis-associated pathogens P. gingivalis and A. actinomycetemcomitans activate human CD14(+) monocytes leading to enhanced Th17/IL-17 responses. European Journal of Immunology 46(9): 2211-2221 DOI 10.1002/eji.201545871.

Di Benedetto A, Gigante I, Colucci S, Grano M. 2013. Periodontal Disease: Linking the Primary Inflammation to Bone Loss. Clinical and Developmental Immunology 3:5037554 DOI $10.1155 / 2013 / 503754$.

Dutzan N, Konkel JE, Greenwell-Wild T, Moutsopoulos NM. 2016. Characterization of the human immune cell network at the gingival barrier. Mucosal Immunology 9(5):1163-1172 DOI 10.1038/mi.2015.136.

Evans HG, Gullick NJ, Kelly S, Pitzalis C, Lord GM, Kirkham BW, Taams, LS. 2009. In vivo activated monocytes from the site of inflammation in humans specifically promote Th17 responses. Proceedings of the National Academy of Sciences of the United States of America 106(15): 6232-6237 DOI 10.1073/pnas.0808144106.

Evans HG, Suddason T, Jackson I, Taams LS, Lord GM. 2007. Optimal induction of T helper 17 cells in humans requires $\mathrm{T}$ cell receptor ligation in the context of Toll-like receptoractivated monocytes. Proceedings of the National Academy of Sciences of the United States of America 104(43):17034-17039 DOI 10.1073/pnas.0708426104.

Geissmann F, Auffray C, Palframan R, Wirrig C, Ciocca A, Campisi L, Lauvau G. 2008. Blood monocytes: distinct subsets, how they relate to dendritic cells, and their possible roles in the regulation of T-cell responses. Immunology and Cell Biology 86(5):398-408 DOI 10.1038/icb.2008.19.

Gonzales JR. 2015. T-and B - cell subsets in periodontitis. Periodontology 2000 69(1): 181-200 DOI 10.111/prd.12090.

Gutcher I, Becher B. 2007. APC-derived cytokines and T cell polarization in autoimmune inflammation. Journal of Clinical Investigation 117(5): 1119-1127 DOI 10.1172/JCI31720. 
417 HöPken UE, Lehmann I, Droese J, Lipp M, Schüler T, Rehm A. 2005. The ratio between

418

419

420

421

422

423

424

425

426

427

428

429

430

431

432

433

434

435

436

437

438

439

440

441

442

443

444

445

446

447

448

449

450 dendritic cells and $\mathrm{T}$ cells determines the outcome of their encounter: proliferation versus deletion. European journal of immunology 35(10): 2851-2863 DOI 10.1002/eji.200526298.

Hajishengallis G. 2009. Porphyromonas gingivalis-host interactions: open war or intelligent guerilla tactics? Microbes and Infection 11(6-7): 637-645 DOI 10.1016/j.micinf.2009.03.009.

Harrington LE, Hatton RD, Mangan PR, Turner H, Murphy TL,Weaver CT. 2005. Interleukin 17-producing CD4+ effector T cells develop via a lineage distinct from the $\mathrm{T}$ helper type 1 and 2 lineages. Nature Immunology 6(11): 1123-1132 DOI 10.1038/ni1254.

Higashi T, Hashimoto K, Takagi R, Mizuno Y, Okazaki Y, Matsushita S. 2010. Curdlan induces DC-mediated Th17 polarization via Jagged1 activation in human dendritic cells. Allergology International 59(2): 161-166 DOI 10.2332/allergolint. 09-OA-0103.

Ito T, Connett JM, Kunkel SL, Matsukawa A. 2012. Notch system in the linkage of innate and adaptive immunity. Journal of Leukocyte Biology 92(1): 59-65 DOI 10.1189/jlb.1011529.

Jain S, Darveau RP. 2010. Contribution of Porphyromonas gingivalis lipopolysaccharide to periodontitis. Periodontology 2000 54(1): 53-70 DOI 10.1111/j.1600-0757.2009.00333.x.

Jiang YQ, Zhao ST, Yang X, Liu Y, Wang CZ. 2015. Dll4 in the DCs isolated from OVAsensitized mice is involved in Th17 differentiation inhibition by 1,25-dihydroxyvitamin D3 in vitro. Journal of Asthma 52(10): 989-995 DOI 10.3109/ 02770903.2015.1056349.

Jiao Z, Wang W, Hua S, Liu M, Wang H, Wang X, Lu, L.2014. Blockade of Notch Signaling Ameliorates Murine Collagen-Induced Arthritis via Suppressing Th1 and Th17 Cell Responses. The American Journal of Pathology 184(4): 1085-1093 DOI 10.1016/j.ajpath.2013.12.010.

Keerthivasan S, Suleiman R, Lawlor R, Roderick J, Bates T, Minter L, Osborne BA. 2011. Notch Signaling Regulates Mouse and Human Th17 Differentiation. Journal of Immunology 187(2): 692-701 DOI 10.4049/jimmunol.1003658.

Meng L, Hu S, Wang J, He S, Zhang Y. 2016. DLL4 + dendritic cells: Key regulators of Notch Signaling in effector $\mathrm{T}$ cell responses. Pharmacological Research 113:449-457 DOI 10.1016/j.phrs.2016.09.001.

Moutsopoulos NM, Kling HM, Angelov N, Jin W, Palmer RJ, Nares S, WahISM. 2012. P orphyromonas gingivalis promotes Th17 inducing pathways in chronic periodontitis. Journa l of Autoimmunity 39(4): 294-303 DOI 10.1016/j.jaut.2012.03.003.

Mukherjee S, Schaller MA, Neupane R, Kunkel SL, Lukacs NW. 2009. Regulation of T Cell Activation by Notch Ligand, DLL4, Promotes IL-17 Production and Rorc Activation. Journal of Immunology 182(12): 7381-7388 DOI10.4049/jimmunol. 0804322. 
451 Novak N, Koch S, Allam J, Bieber T. 2010. Dendritic cells: Bridging innate and adaptive 452 immunity in atopic dermatitis. Journal of Allergy and Clinical Immunology 125(1): 50-59 DOI 10.1016/j.jaci.2009.11.019.

454

455

456

457

458

459

460

461

462

463

464

465

466

467

468

469

470

471

472

473

474

475

476

477

478

479

480

481

482

483

Okui T, Aoki Y, Ito H, Honda T, Yamazaki, K. 2012. The presence of IL-17+/FOXP3+ doublepositive cells in periodontitis. Journal of Dental Research 91(6):574-579 DOI 10.1177/0022034512446341.

Park H, Li Z, Yang XO, Chang SH, Nurieva R, Wang YH, Dong C. 2005. A distinct lineage of CD4 $\mathrm{T}$ cells regulates tissue inflammation by producing interleukin 17. Nature Immunology 6(11): 1133-1141 DOI 10.1038/ni1261.

Roberts CA, Dickinson AK, Taams LS. 2015. The Interplay Between Monocytes/Macrophages and CD4(+) T Cell Subsets in Rheumatoid Arthritis. Frontiers in Immunology 6: 571-577 DOI 10.3389/fimmu.2015.00571.

Rossol M, Meusch U, Pierer M. 2007. Interaction between TNF and TNFR1/2 Mediates the Activation of monocytes by contac with T cells. The Jouranl of Immunology 179(6):42394248 DOI 10.4049.jimmunol.179.6.4239.

Segura E, Touzot M, Bohineust A, Cappuccio A, Chiocchia G, Hosmalin A, Amigorena S. 2013. Human inflammatory dendritic cells induce Th17 cell differentiation. Immunity 38(2) : 336-348 DOI 10.1016/j.immuni.2012.10.018.

Seo T, Cha S, Kim T, Lee J, Woo KM. 2012. Porphyromonas gingivalis-derived lipopolysaccharide-mediated activation of MAPK signaling regulates inflammatory response and differentiation in human periodontal ligament fibroblasts. The Journal of Microbiology 50(2): 311-319 DOI 10.1007/s12275-012-2146-x.

Su H, Yan X, Dong Z, Chen W, Lin ZT, Hu QG. 2015. Differential roles of Porphyromonas gingivalis lipopolysaccharide and Escherichia coli lipopolysaccharide in maturation and antigen-presenting functions of dentritic cells. European Review for Medical and Pharmacological Science 19(13): 2482-2492.

Tsao PN, Wei SC, Huang MT, Lee MC, Chou HC, Chen CY, Hsieh, WS. 2011. Lipopolysaccharide-induced Notch signaling activation through JNK-dependent pathway regulates inflammatory response. Journal of Biomedical Science 18(1): 56-65 DOI 10.1186/1423-0127-18-56.

Veldhoen M, Hocking RJ, Atkins CJ, Locksley RM, Stockinger B. 2006. TGF beta in the context of an inflammatory cytokine milieu supports de novo differentiation of IL-17producing T cells. Immunity 24(2): 179-189 DOI 10.1016/j.immuni.2006.010001. 
484

485

486

487

488

489

490

491

492

493

494

495

496

497

498

499

500

501

502

503

504

505

506

507

508

509

510

511

512 513 significant difference (ns), ${ }^{*} p<0.05,{ }^{* *} p<0.01$. Scientific Reports 5: 8234 DOI 10.1038/srep08234. DOI 10.1007/s10753-017-0638-X. DOI 10.1111/apm.12629. 0.1016/j.archoralbio.2019.104483.

Figure legends:

Wang Y, Xing F, Ye S, Xiao J, Di J, Zeng S, Liu J. 2015. Jagged-1

signaling suppresses the IL-6 and TGF- $\beta$ treatment-induced Th17 cell differentiation via the reduction of ROR $\gamma \mathrm{t} / \mathrm{IL}-17 \mathrm{~A} / \mathrm{IL}-17 \mathrm{~F} / \mathrm{IL}-23 \mathrm{a} / \mathrm{IL}-12 \mathrm{rb}$.

Weng C, Chong L, Jia X, Zheng R, Huang Y, Zhu T, Zhang W. 2017. Anti-D114 Antibody Inhibits the Differentiation of Th17 Cells in Asthmatic Mice. Inflammation 40(6): 1975-1982

Wittmann M, Alter M, Stünkel T. 2004. Cell-to-cell contact between activated CD4+ T lymphocytes and unprimed monocytes interferes with a TH1 response. Journal of Allergy and Clinical Immunology 114(4): 965-973 DOI 10.1016/j.jaci.2004.06.033.

Yang H, Wang J, Li Y, Yin Z, Lv T, Zhu P, Zhang Y. 2017. CD147 modulates the differentiation of T-helper 17 cells in patients with rheumatoid arthritis. Apmis 125(1): 24-31

Zhang LP, Gao L, Xu CR, Li X, Wang PP, Zhang C, Zhao CJ. 2019. Porphyromonas gingi valis lipopolysaccharide promotes T- helper 17 cell differentiation from human CD4+ naïve T cells via toll-like receptor-2 in vitro. Archivesof Oral Biology 107:104483-104489 DOI 1

Zhou L, Ivanov II, Spolski R, Min R, Shenderov K, Egawa T, Littman DR. 2007. IL-6 programs $\mathrm{T}(\mathrm{H})-17$ cell differentiation by promoting sequential engagement of the IL-21 and IL-23 pathways. Nature Immunology 8(9): 967-974 DOI 10.1038/ni1488.

Fig. 1. Effect of $P$. gingivalis lipopolysaccharide-treated $\mathrm{CD}_{14}^{+}$monocytes on Th17 cell differentiation. mRNA expression levels of IL-17 (A-C) and RORC (D-F) in the presence or absence of $P$. gingivalis lipopolysaccharide were determined using qRT-PCR. (G) Dot plots show the proportion of Th17 cell differentiation determined by using flow cytometry. (H-J) Frequencies of Th17 cells in each of the three co-culture ratios analyzed using flow cytometry. Data are presented as mean $\pm \mathrm{SD}$ of triplicate assays for six independent experiments(n=6). CD14 monocytes (Mo), lipopolysaccharide (LPS), retinoid-related orphan receptor C (RORC), no

Peer) reviewing PDF | (2019:06:38772:1:1:NEW 29 Jan 2021) 
515 Fig. 2. Expression of IL-1 $\beta$, IL-6, TGF- $\beta$, and IL-23 in P. gingivalis lipopolysaccharide-treated

$516 \mathrm{CD}^{+} 4^{+}$monocytes. mRNA expression levels of IL-1 $\beta$ (A), IL-6 (B), TGF- $\beta$ (C), and IL-23 (D)

517 determined using qRT-PCR. Levels of IL-1 $\beta$ (E), IL-6(F), TGF- $\beta(\mathrm{G})$, and IL-23 (H) secreted by

$518 \mathrm{CD} 4^{+}$monocytes in the presence or absence of $P$. gingivalis lipopolysaccharide detected using

519 ELISA. Data are presented as mean \pm SD of triplicate assays for six independent experiments

520 (n=6). P. gingivalis lipopolysaccharide (Pg-LPS), $* p<0.05, * * p<0.01, * * * p<0.001$.

521

522 Fig. 3. Role of cell-cell contact in the Th17 cell response induced by $P$. gingivalis 523 lipopolysaccharide-activated $\mathrm{CD}^{+} 4^{+}$monocytes. $\mathrm{CD} 14^{+}$monocytes and $\mathrm{CD}^{+} \mathrm{T}$ cells were 524 cultured in transwells for 3 days, and the expression of IL-17 (A) and RORC (B) mRNA in the 525 presence or absence of $P$. gingivalis lipopolysaccharide was determined. (C) Dot plots show the 526 proportion of Th17 cell differentiation determined using flow cytometry. (D) Frequency of Th17

527 cells in each group determined by using flow cytometry. Data are presented as mean \pm SD of 528 triplicate assays for six independent experiments $(n=6)$. Transwell (TW), lipopolysaccharide 529 (LPS), retinoid-related orphan receptor C (RORC), no significant difference (ns).

530

531 Fig. 4. Expression of Jagged-1 (A) and Dll-4 (B) mRNA in the presence or absence of P. gingivalis 532 lipopolysaccharide. Data are presented as mean \pm SD of triplicate assays for six independent 533 experiments (n=6). P. gingivalis lipopolysaccharide (Pg-LPS), Delta-like ligand 4 (D1l-4), no 534 significant difference (ns), **p $<0.01$. 
536 Fig. 5. Role of Dll-4 in the Th17 cell differentiation induced by $P$. gingivalis lipopolysaccharide537 activated $\mathrm{CD} 14^{+}$monocytes. $\mathrm{CD} 14^{+}$monocytes were pretreated with 5 and $10 \mu \mathrm{g} / \mathrm{mL}$ anti-D $11-4$ 538 antibody, for 90 min prior to addition of the $P$. gingivalis lipopolysaccharide. The cells were then 539 cocultured with the activated $\mathrm{CD}^{+} \mathrm{T}$ cells for 5 days. (A) Dot plots show the proportion of Th17 540 cell differentiation determined using flow cytometry. (B) Frequency of Th17 cells in each group 541 determined using flow cytometry. (C) Protein level of IL-17 detected using western blotting. 542 GAPDH was used as the protein loading control. (D) The intensified bands of IL-17 were measured 543 using Image J software and were normalized to GADPH. (E) IL-17 concentration in the supernatant 544 of the co-cultured cells measured after 5 days using ELISA. Data are presented as mean $\pm \mathrm{SD}$ of 545 triplicate assays for six independent experiments $(\mathrm{n}=6)$. P.gingivalis lipopolysaccharide (Pg-LPS),

546 Delta-like ligand 4 (Dll-4), ${ }^{*} p<0.05,{ }^{* *} p<0.01,{ }^{* * *} p<0.001$.

547

548

549

550 


\section{Figure 1}

Effect of $P$. gingivalis I ipopolysaccharide -treated $\mathrm{CD} 14{ }^{+}$monocytes on Th17 cell differentiation.

Fig.1. Effect of $P$. gingivalis I ipopolysaccharide -treated $\mathrm{CD} 14^{+}$monocytes on Th17 cell differentiation . mRNA expression levels of IL-17 (A) and ROR C (B) in the presence or absence of $P$. gingivalis lipopolysaccharide were determined using qRT-PCR. (C) Dot plots show the proportion of Th17 cell differentiation determined by using flow cytometry. (D) Frequencies of Th17 cells in each of the three coculture ratios analyzed using flow cytometry. Data are presented as mean \pm SD of triplicate assays for six independent experiments $(n=6)$. CD14 ${ }^{+}$monocytes (Mo), I ipopolysaccharide (LPS), retinoid-related orphan receptor C (RORC), n o significant difference (ns), *p<0.05, ** $p<0.01$. 
A

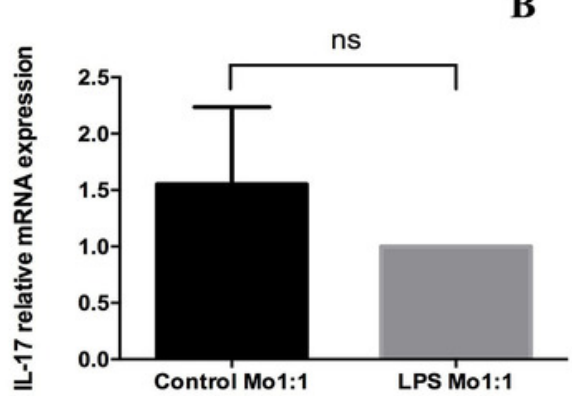

D

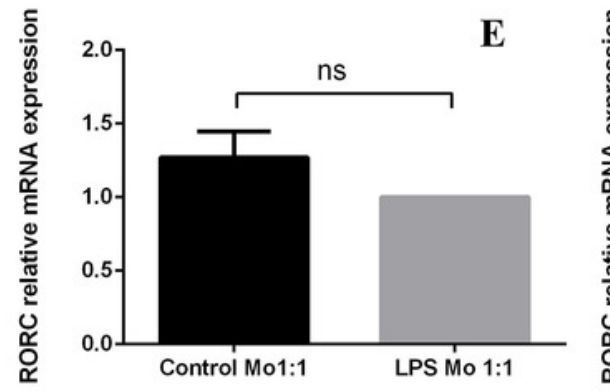

B
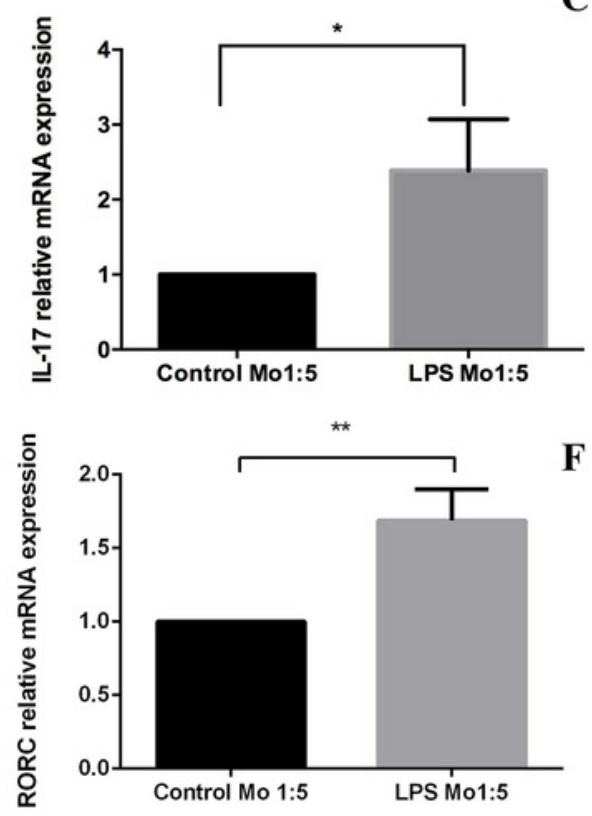

C
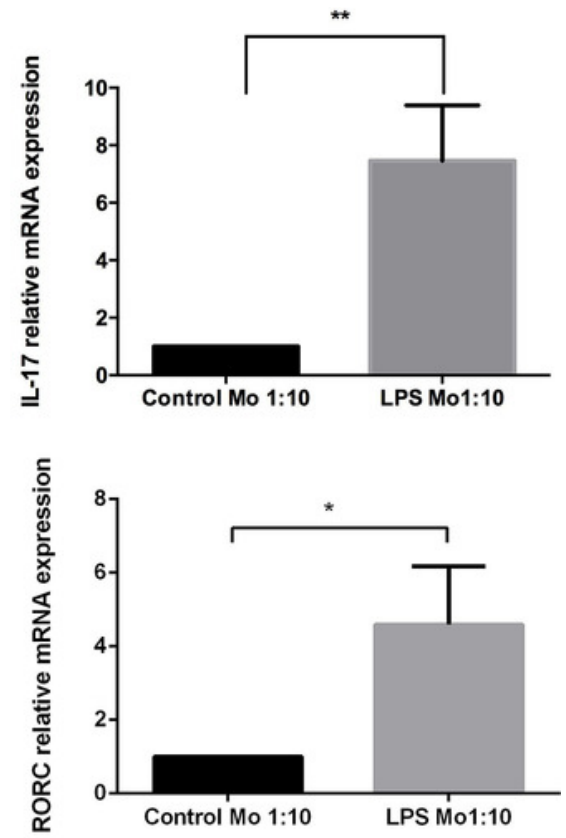

G
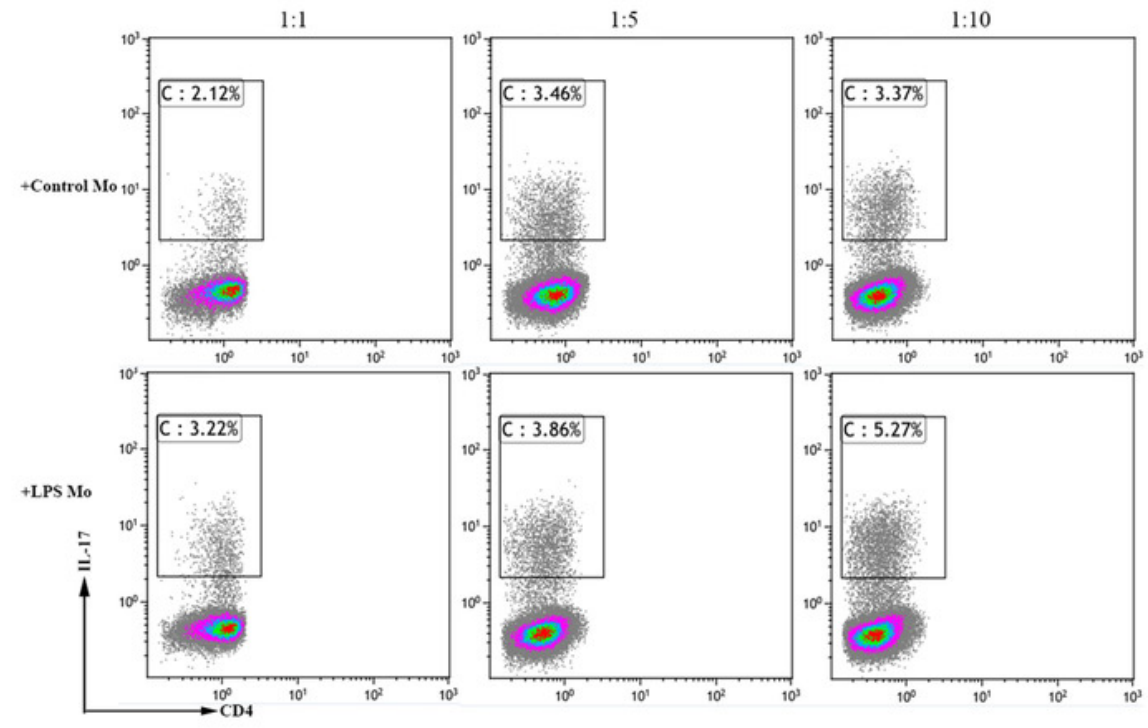

H
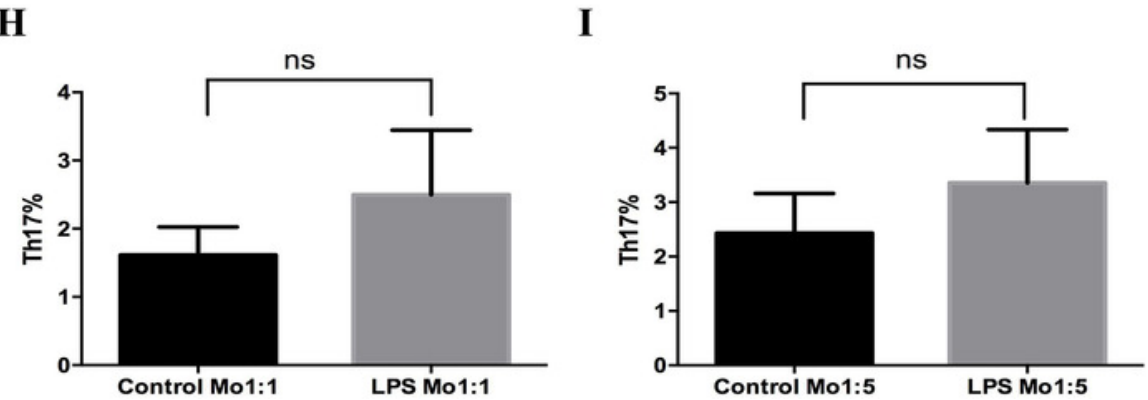

$\mathbf{J}$

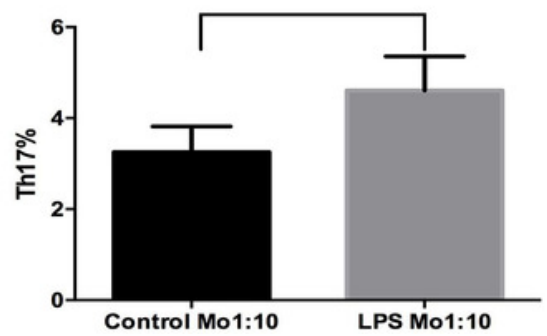




\section{Figure 2}

Expression of IL-1 $\beta$, IL-6, TGF- $\beta$, and IL-23 in $P$. gingivalis lipopolysaccharide -treated CD14 ${ }^{+}$monocytes

Fig. 2. Expression of IL-1 $\beta$, IL-6, TGF- $\beta$, and IL-23 in $P$. gingivalis lipopolysaccharide -treated CD14 ${ }^{+}$ monocytes . (A) mRNA expression levels of IL-1 $\beta$, IL-6, TGF- $\beta$, and IL-23 determined using qRT-PCR. (B) Levels of IL-1 $\beta$, IL-6, TGF- $\beta$, and IL-23 secreted by CD14 ${ }^{+}$monocytes in the presence or absence of $P$. gingivalis lipopolysaccharide detected using ELISA. Data are presented as mean \pm SD of triplicate assays for six independent experiments $(\mathrm{n}=6)$. $P$. gingivalis I ipopolysaccharide (Pg-LPS), $* p<0.05, * * p<0.01, * * * p$ $<0.001$.

A
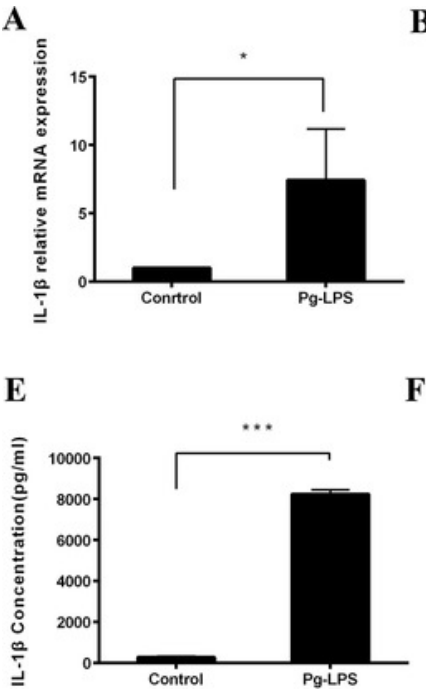

$\mathbf{F}$
B
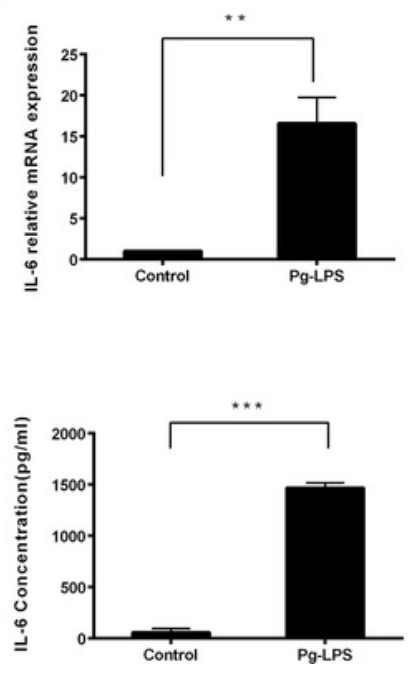

C
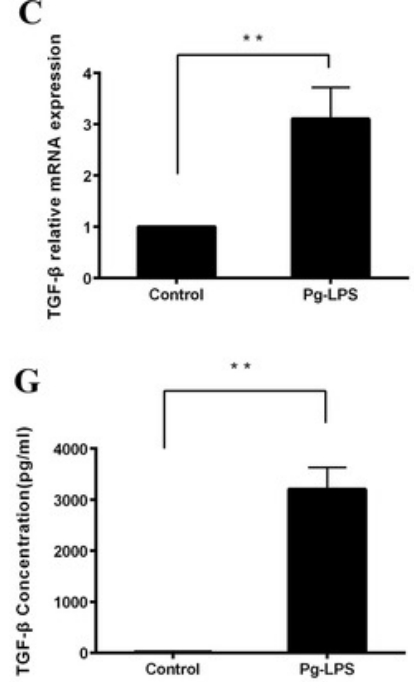

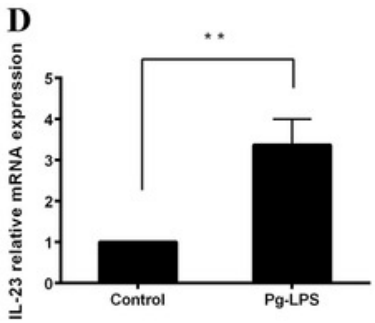

H

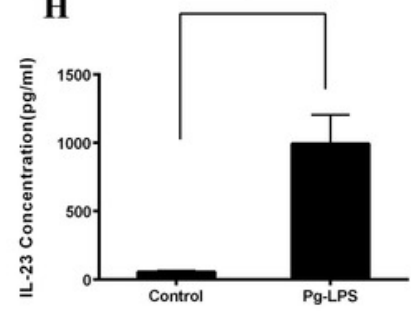




\section{Figure 3}

Role of cell-cell contact in the Th17 cell response induced by $P$. gingivalis lipopolysaccharide -activated CD14 ${ }^{+}$monocytes.

Fig. 3. Role of cell-cell contact in the Th17 cell response induced by $P$. gingivalis lipopolysaccharide activated $\mathrm{CD} 14{ }^{+}$monocytes. $\mathrm{CD} 14{ }^{+}$monocytes and $\mathrm{CD} 4{ }^{+} \mathrm{T}$ cells were cultured in transwells for 3 days, and the expression of IL-17 (A) and retinoid-related orphan receptor C (B) mRNA in the presence or absence of $P$ . gingivalis lipopolysaccharide was determined. (C) Dot plots show the proportion of Th17 cell differentiation determined using flow cytometry. (D) Frequency of Th17 cells in each group determined by using flow cytometry. Data are presented as mean \pm SD of triplicate assays for six independent experiments $(n=6)$. T ranswell (TW), lipopolysaccharide (LPS), retinoid-related orphan receptor $C$ (RORC), n o significant difference (ns) .

A

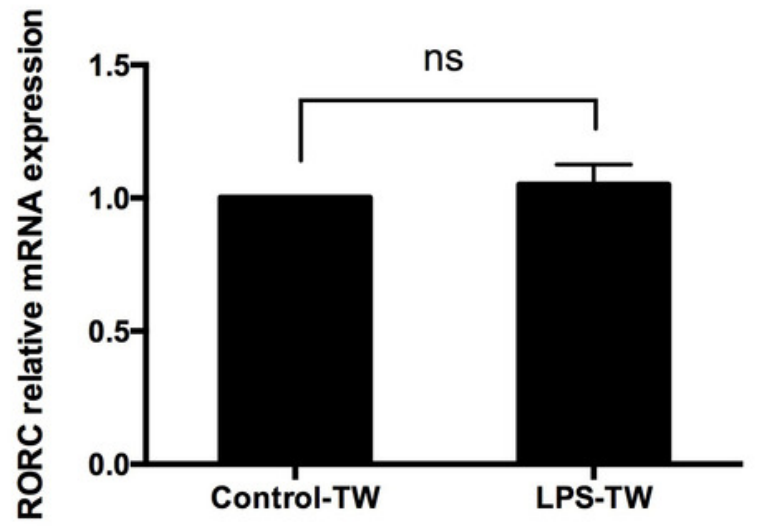

$\mathbf{C}$

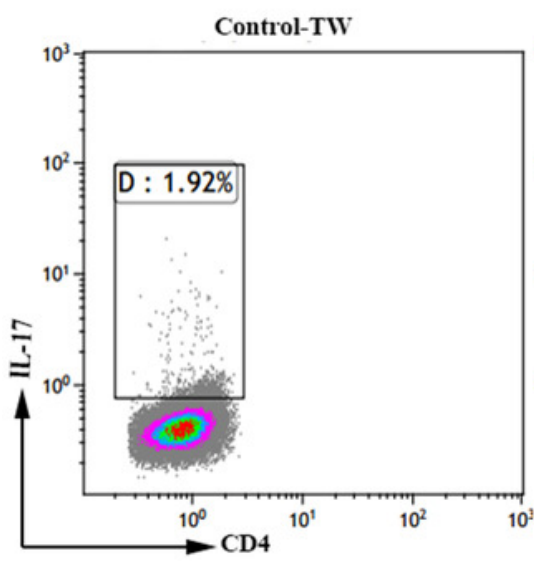

LPS-TWV

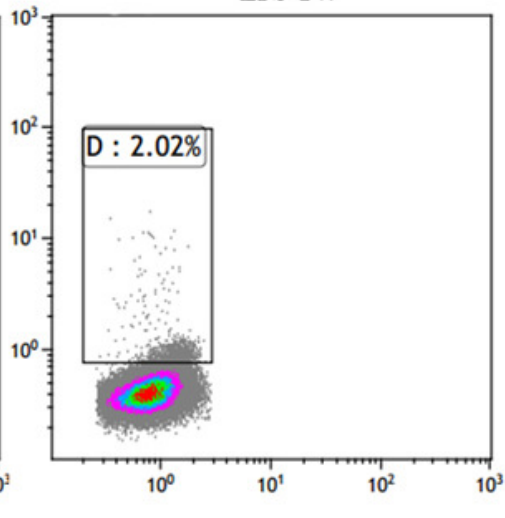

B

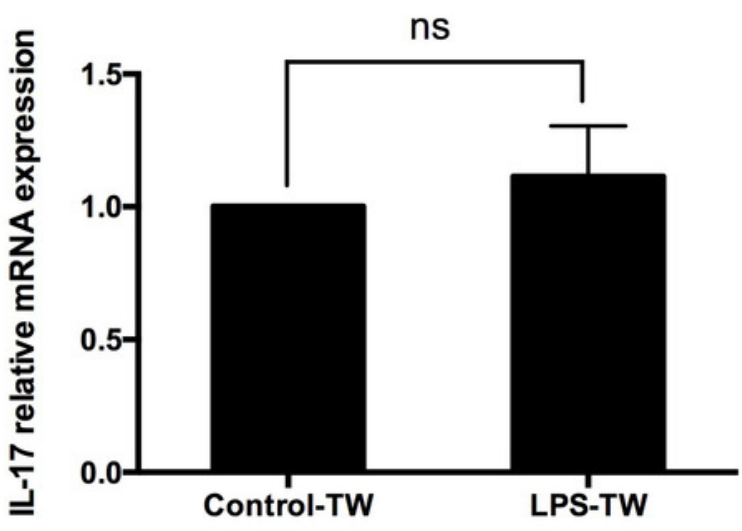

D

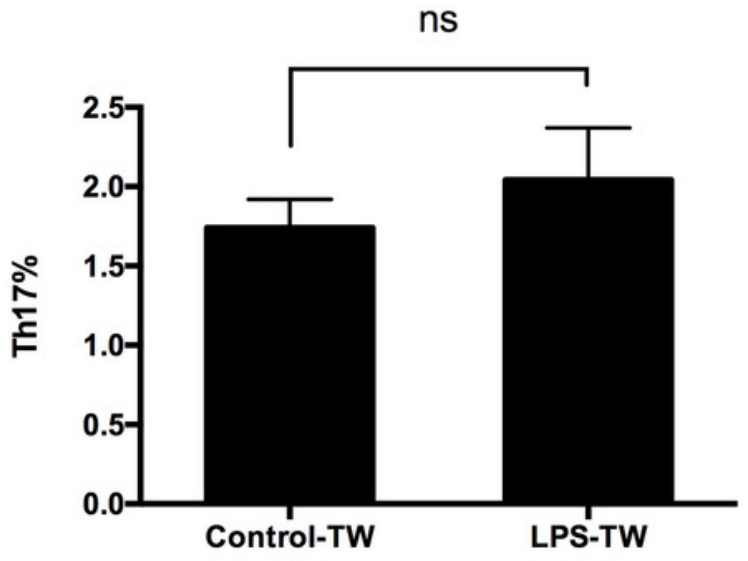


Figure 4

Expression of Jagged-1 (A) and DII-4 (B) mRNA in the presence or absence of $P$. gingivalis lipopolysaccharide .

Fig. 4. Expression of Jagged-1 (A) and Dll-4 (B) mRNA in the presence or absence of $P$. gingivalis lipopolysaccharide. Data are presented as mean \pm SD of triplicate assays for six independent experiments $(n=6) . P$. gingivalis I ipopolysaccharide (Pg-LPS), Delta-like ligand 4 (DIl-4), $n$ o significant difference (ns) , $* * p<0.01$.

A

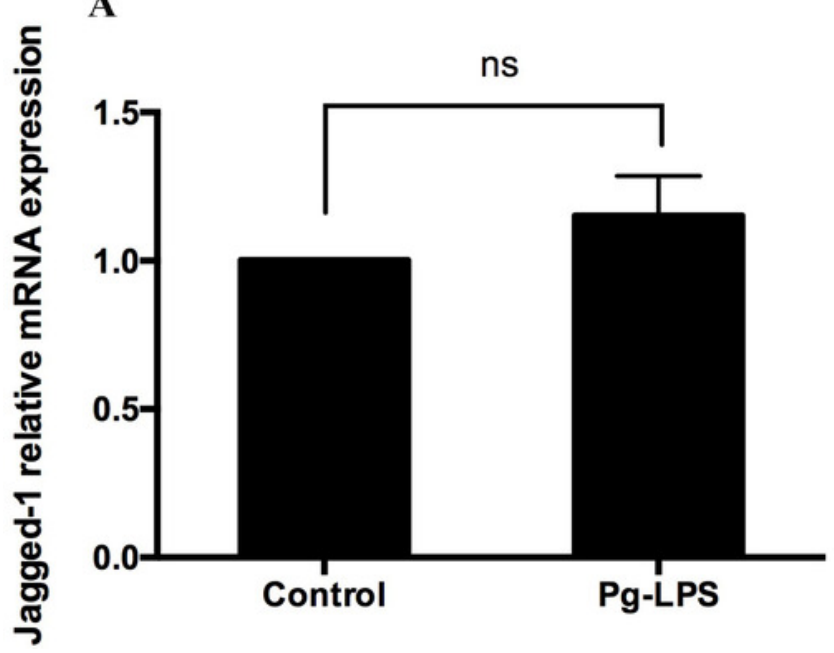

B

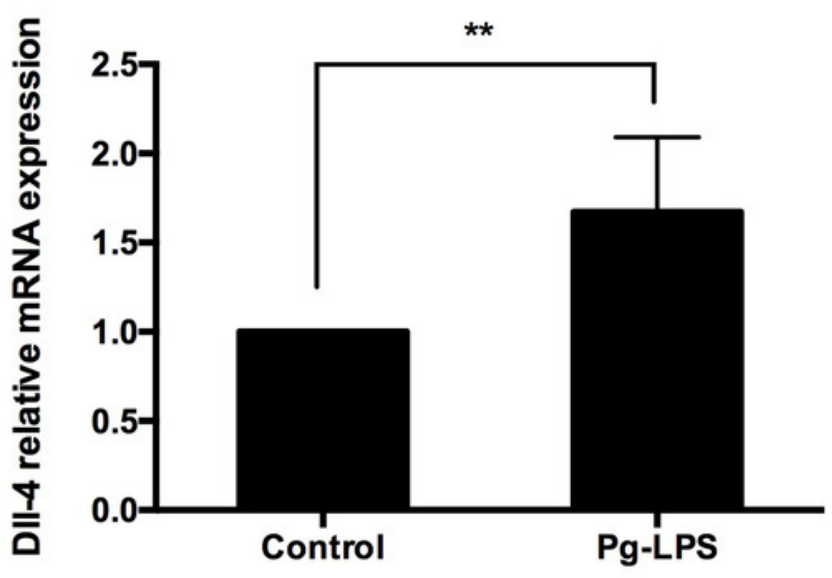




\section{Figure 5}

Role of DII-4 in the Th17 cell differentiation induced by $P$. gingivalis lipopolysaccharide -activated CD14 ${ }^{+}$ monocytes.

Fig. 5. Role of DIl-4 in the Th17 cell differentiation induced by $P$. gingivalis lipopolysaccharide -activated CD14 ${ }^{+}$monocytes. CD14 ${ }^{+}$monocytes were pretreated with 5 and $10 \mu \mathrm{g} / \mathrm{mL}$ anti-DII-4 antibody, for 90 min prior to addition of the $P$. gingivalis lipopolysaccharide. The cells were then cocultured with the activated $\mathrm{CD} 4{ }^{+} \mathrm{T}$ cells for 5 days. (A) Dot plots show the proportion of Th17 cell differentiation determined using flow cytometry. (B) Frequency of Th17 cells in each group determined using flow cytometry. (C) Protein level of IL-17 detected using western blotting. GAPDH was used as the protein loading control, and the intensified bands were measured using ImageJ software and were normalized to GADPH. (D) IL-17 concentration in the supernatant of the co-cultured cells measured after 5 days using ELISA. Data are presented as mean \pm SD of triplicate assays for six independent experiments $(n=6)$. $P$. gingivalis I ipopolysaccharide (Pg-LPS), Deltalike ligand 4 (DII-4), * $p<0.05, * * p<0.01, * * * p<0.001$.

A
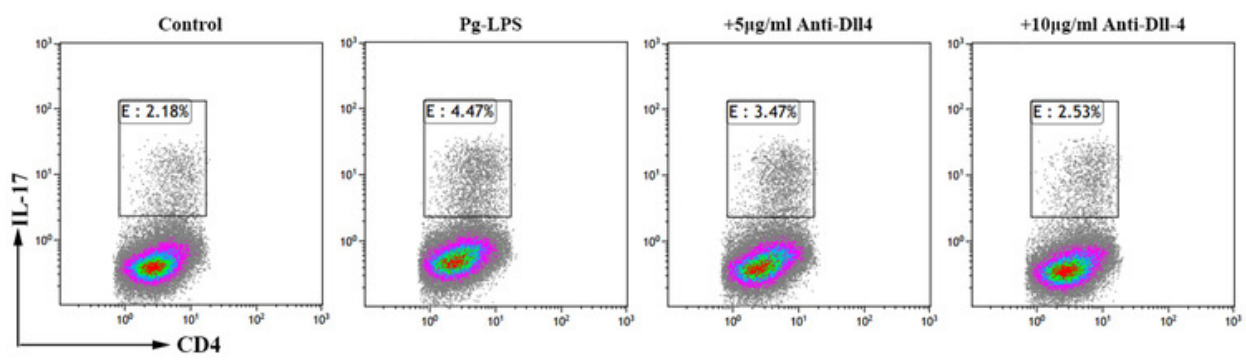

C

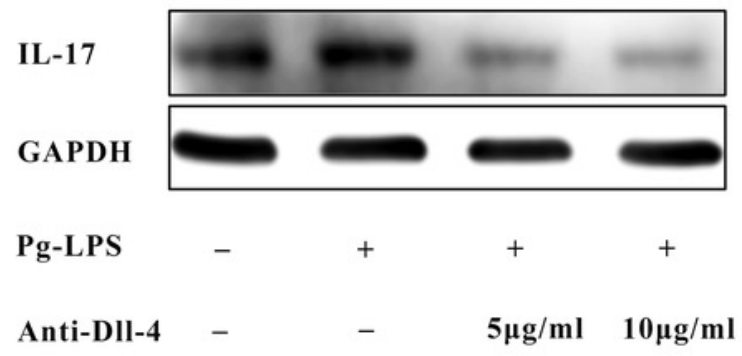

B

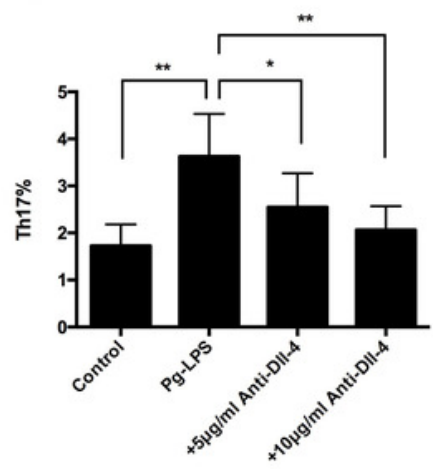

E

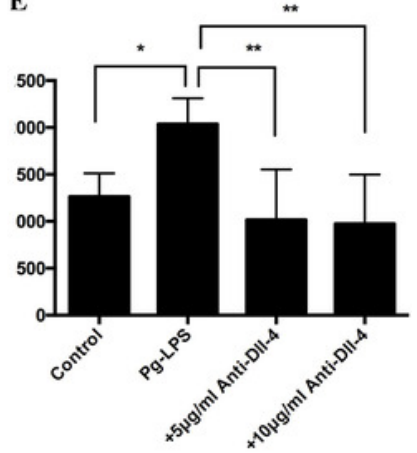




\section{Table $\mathbf{1}$ (on next page)}

Primer sequences for quantitateive reverse transcription-polymerase chain reaction

TABLE 1 Primer sequences for quantitateive reverse transcription-polymerase chain reaction 
2 TABLE 1 Primer sequences for quantitateive reverse transcription-polymerase chain reaction

3

\begin{tabular}{lll}
\hline Gene & \multicolumn{1}{c}{ Forward sequence $\left(5^{\prime}-3^{\prime}\right)$} & \multicolumn{1}{c}{ Reverse sequence $\left(5^{\prime}-3^{\prime}\right)$} \\
\hline RORC & ACAGAGATAGAGCACCTGGT & CACATCTCCCACATGGACTT \\
IL-17 & ACGAAATCCGGATGCCCAA & TGCGGTGGAGATTCCAAGGT \\
Jagged-1 & ATGATGGGAACCCGATCAAG & TCACCAAGCAACAGATCCAA \\
DIl-4 & GCAAACAGCAAAACCACACA & CACACAGACTGGTACATGGA \\
IL-1 $\beta$ & TGAGCACCTTCTTTCCCTT & ATGGACCAGACATCACCAA \\
IL-6 & CCTTCCAAAGATGGCTGAAA & CTGGCTTGTTCCTCACTACT \\
TGF- $\beta$ & CTGTAATGCTGCTGTTGCT & CTTAGATCCATGTGTGTCCCAC \\
IL-23 & GTGGAAACCCACAACGAAAT & TTTAACTTAGCCTCAGCAGA \\
$\beta$-action & TGGGACGACATGGAGAAAA & GGGGTGTTGAAGGTCTCAAA \\
\hline
\end{tabular}

4 